\title{
Effects of Stigma and Discrimination on the Right to Education of Children with HIVIAIDS Aged 4-8 Years in Kikuyu Sub-county, Kenya
}

\author{
Mary Nginya, Paul A. Odundo, Amir Kabunga Boniface Ngaruiya, Ruth W. M. Kahiga, \\ Evanson M. Muriithi \\ Department of Educational Communication and Technology, College of Education and External Studies, University of Nairobi, Nairobi, \\ Kenya
}

\section{Email address:}

marynginya@gmail.com (M. Nginya),odundopaul@yahoo.com (P. A. Odundo)

\section{To cite this article:}

Mary Nginya, Paul A. Odundo, Amir Kabunga Boniface Ngaruiya, Ruth W. M. Kahiga, Evanson M. Muriithi. Effects of Stigma and Discrimination on the Right to Education of Children with HIV/AIDS Aged 4-8 Years in Kikuyu Sub-county, Kenya. International Journal of Elementary Education. Vol. 5, No. 1, 2016, pp. 1-7. doi: 10.11648/j.ijeedu.20160501.11

\begin{abstract}
Childrens Act 2001 and the Kenyan constitution emphasize on the right to free and compulsory basic education for all school age children. However, orphaned and vulnerable children have always remained on the receiving end as they are limited in the participation in learning due to their status, which include HIV/AIDS. Achievement and participation of children with HIV/AIDS (CWHA) has been impaired by stigma and discrimination (S\&D) among CWHA manifest in ways such as isolation in the sitting arrangement and rejection during play activities. CHWA suffered S\&D in form of name-calling like kahurura, and physical abuse through beating and over punishment which negatively impair participation in learning activities. S\&D impede sustainability and achievement of CWHA in the school systems that eventually drop out of school or continuously perform poor and gain nothing out of the years they spend in school. This study aimed at establishing the effects of S\&D on the right to education of CWHA aged 4-8 years. The target population included 680 HIV/AIDS orphans and vulnerable children (OVC), 120 pre-school teachers, 240 caregivers and 34 administrators of civil society organizations (CSOS). A sample of 68 OVCs, 4 CSOs, 12 teachers, and 24 caregivers were randomly selected and a survey design was used. Data was collected through questionnaires, interview schedules, storytelling sessions and observation schedules. The study established that CWHA were isolated in the sitting arrangement and separation of items and during class activities. In schools where there is no isolation children integrate and learn smoothly. Rejection was profound during play and group activities among CWHA. Further the study found out that CWHA were neglected by relatives, peers, community and the teacher. This was manifested through being left to work and meet their basic needs. HIV/AIDS orphans lack basic needs which lead to withdrawal and self-pity and eventually poor performance or dropping out of school. The findings revealed that CWHA who stayed with relatives suffered physical abuse by being over punished through physical beating and over working. From the study it was evident that CWHA suffered from name calling and labelling which led to low self-esteem, withdrawal in turn barring sustainability of integration of CWHA in the school system. The study recommended creating conducive environment that will make the society to appreciate and support CWHA. Policies should be put in place to enhance access to education by CWHA without discrimination.
\end{abstract}

Keywords: Children with HIV/AIDS, Discrimination, Stigma, Isolation, Rejection, Right to Education

\section{Introduction}

Education is essential for human development through universal access by all children across varied socio-economic background. Children have a right to education as stipulated by the Child Act 2001 which states the right to protection of all children against any form of discrimination.Children should access education in non-stigmatized and nondiscriminated environment including school system according to the UN CRC [1]. Children have a right to free and compulsory education while enjoying right to nondiscrimination regardless of health status, socio-economic background, ethnic or religious affiliation (UN, CRC [1]. In 
support of this position, the government of Kenya through Child Act 2001 criminalised stigma and discrimination (S\&D) within the school system as a strategy of increasing access and participation within the school system by all children including those from under privileged segments of the Kenyan society. This has further been entrenched in the Kenya constitution 2010 which underscores right to education as a strategy of eliminating all forms of S\&D as a pathway for realizing sustainable development.

Based on this realization the most disadvantaged segment of children within the school system are those living with HIV/AIDS who are more often than not suffer from sustained S\&D. According to Journal for the International AIDS Society (JIAS) [2] during the UN conference in 2011, commitment to reducing HIV/AIDS related S\&D through programmes, policies, protective laws, appropriate legal, social and policy frameworks was launched and governments asked to implement. CWHA can be sustained in the learning institutions if HIV/AIDS related S\&D can be eliminated and allowing integration.

However, children face a mileage of challenges in their quest to attain education. As such HIV/AIDS related stigma continues to alienate learners from integration in schools, for the reason that they are 'different' from 'others'. This has led to withdrawal, poor performance and eventual drop out of CWHA from the school system. Parker \& Aggleton [3] framework on stigma purport that stigma is part of compounded social tussles that creates and disseminates social disparities including for CWHA who suffer loss of face and therefore poor participation in learning activities. Where no stigma exists, children are considered equal and there is sustainability of learning participation.

To understand stigma, Link \& Phelan [4] conceptualised it as a merge of solid mechanisms in that it transpires when changes are labelled, connected to a deleterious label, that categorizes people as different leading to victimization HIV/AIDS related stigma differentiates CWHA from the 'normal' children excluding them from normal participation in activities both in and outside the school. Parker \& Aggleton [3] define HIV/AIDS stigma as shared disgrace and traditional occurrences ingrained in group circumstances. This devalues the individuals that are set aside due to their HIV/AIDS status. Stigma shames or diminishes individuals and is deduced as socially fashioned development based on the categorization of personal qualities as different and exceedingly unwanted. On the other hand, discrimination is viewed as stigma in action. HIV/AIDS related Stigma blocks integration of CWHA from school system as they are seen to be different from the peers.

Public stigma is fundamental to Pryor and Reedels ideal that denote people shared and inner responses to individual they see to have slurred form (Goffman, Visser and colleagues $[5,6]$. This leads to labelling of CWHA and in turn hinders their learning participation According to Dijker and Koomen and Weiner, Perry and Magnusson [7, 8], public stigma encompasses the intellectual emotional and social responses of those who defame such as teachers, peers and guardians. The sources of stigmatization emanate in the cognitive pictures teachers, peers and guardians embrace visà-vis those who poses the stigmatized state, CWHA. Intellectual symbol of stigmatized state can prompt undesirable emotive and social responses. Such a situation may lead teachers and guardians of children with LD to become hostile to the child, isolate, reject or discriminate the child, posing danger on the participation of 3 the child in learning activities. Another factor is where the teacher, peers or the parent expresses anxiety and sympathy towards the child with LD [8]. Dijker \& Koomen and Hebl, Tickle and Heatherton [7, 9] found out that, such reactions can cause emotional ambivalence and awkward interactions between the perceiver and the target. This may lead negative effects on the participation of CWHA in learning activities. Bos, Kok \& Dijker and Feldman and Crandall $[10,8]$ adds that perceivers may view CWHA as a danger to their health. This may elicit fear and avoidance especially to teachers in the private schools. LD stigma associated with the low performance of CWHA may arise and result in dropout of the child.

Self-stigma mirrors the social and psychological effects of having a stigma [5]. It includes both the nervousness of being exposed to HIV/AIDS stigmatization and the latent internalization of the deleterious beliefs and emotion associated with HIV/AIDS stigma. Various studies had shown that stigma had negative concerns for inner wellbeing of stigmatized persons11, 12]. Self stigma can emanate from an awareness of public stigma as CWHA are profoundly aware of the social deflation coupled with their condition. Like public stigma Mak and Cheung [13] highlight that selfstigma has intellectual, affection and behavioural components and functions at both obvious and at the embedded level [14].

Public stigma impacts the self in three ways; enacted stigma which is the destructive handling of an individual having stigmatized condition; felt stigma which is the knowledge of anticipated stigmatization on the part of the individual with a stigmatized condition and though internalized stigma which is the lessening of self-worth and associated psychological agony experienced by CWHA condition (Herek, [15]. Apprehensions regarding who to tell and the distress of being discovered are substantial sources of psychological anguish among children who hide their HIV/AIDS status Panchankis [16] for instance children who could possibly organized as a result where as those who disclose their HIV/AIDS conditions do not undergo through nervousness their attempt to disclose their concerns they still must withstand the probability of continually being humiliated in the eyes of the teachers and their schoolmates without HIV/AIDS [17].

Herek, Saha and Burack [18] carried a study to establish how felt and self-stigma impact on the psychological wellbeing of CWHA. The study by Herek et al. [18] found that it was worth to realize the importance of recognizing the possible negative consequences that emanate from felt and self-stigma and discrimination. The negative impacts of S\&D bar CWHA in their quest to participate in learning activities, Stigma by association corresponds to Goffman's [5] courtesy stigma and involves shared and emotional responses to people linked to a 
stigmatized and discriminated person. Guardians, peers and teachers face HIV/AIDS stigma for being associated with affected and infected children. This makes them shy away from CWHA hence failing to give support.

Stigma by association like public stigma and self-stigma encompasses affective, behavioural and cognitive aspects [13]. In addition stigma by association entails two processes; unambiguous attitudes that are reasonable in moderating the spread of stigma across cohorts with a meaningful relationship like a family member. The second process is embedded attitudes that moderate the spread of stigma when the link is purely illogical as well as when the link is more meaningful [19]. Perceptions of stigma by association have been linked to low self-esteem and psychological distress among guardians. Siblings and teachers of CWHA Mak \& Kwok [21], this can lead to the child not being enrolled in school or not being supported to achieve academically. Guardians, siblings and teachers in normal circumstances conceal their relationship with CWHA Phelan, Bromet and Link [22] or encourage the child to conceal their status. Sutterheim et al, (2009) [23] explains that such camouflage "advice" is harmful to the psychological well-being of the stigmatized CWHA, thereby affecting their participation in learning processes. Snyder, Omoto and Crain [24], add that stigma by association too may affect other family members who establish asocial relationship with CWHA who experience HIV/AIDS stigma. These include friends and caregivers of CWHA.

According to Bos, Pryor \& Reeder [25], Corrigan and Lam [26], structural stigma is defined as the "legitimatization and perpetuation of a stigmatized status by society's institutions and ideological systems" Labelling of children as CWHA in school legitimizes and perpetuates HIV/AIDS stigma on children perceived not to achieve academically. Studies carried out by Campbell \& Deacon, Link and Phelan, Parker and Aggleton, Scambler and Paoli [4, 3, 27] indicated stigma recycles prevailing social inequalities and is propagated by supremacy and the exercise of social, economic, and political power. As a result, the scrutiny of structural stigma in the school necessitates the scrutiny of the social framework in which that stigma occurs and the local awareness that contribute to structural stigma.

Stutterheim et al., (2011) [17], indicated that CWHA suffered stigma in form of isolation, from teachers and peers in school who fear being infected. CWHA are isolated in the sitting arrangement, separation of items and when lining up during play time. Where children are integrated in the main stream without isolation there is sustainability of learning participation. Non- discrimination protects children from rejection as children deserve care and love from the adults within their environment. Rejection of CWHA by relatives, teachers, peers and the community due to HIV/AIDS related stigma has also been highlighted [28, 2]. Rejection is seen through abandonment and neglecting of orphans by relatives. CWHA fend for themselves without anyone caring for them. Where children are cared for and their needs met, children feel appreciated and loved, raising their self- esteem and in turn participating in the learning activities. UNICEF [29] reported that in Kenya, CWHA were sent out of school for fear of infecting others by teachers.

UN, CRC (1991) [1] protects children against any form of torture or harm that can cause physical or emotional harm. S\&D related to HIV/AIDS manifested through physical abuse has also been reported. The peers also teased and harassed CWHA making it stigmatizing thus hindering integration of CWHA in the main stream. Bauman, Camacho, Siluer, Hudis and Draimin [28] confirmed that children orphaned by HIV/AIDS encounter hostility from their extended families \& community in addition to facing rejection and denial to accessing schooling and healthcare services.

According to UN, CRC (1991) [1], CWHA should be protected against verbal abuse to enhance their social, emotional and moral development. Successful learning participation is enhanced by high self-esteem. As much as there are policies and frameworks have been put in place to protect children (internal HIV/AIDS Alliance still suffers S\&D which affect their participation in 7 learning. In addition, UNICEF [29] established that CWHA suffered shame and embarrassment emanating from their condition. The peers also teased and harassed CWHA making it stigmatizing thus hindering integration of CWHA in the main stream.

The government of Kenya through sessional paper on education training has emphasized the intention for the policy in mitigating the circumstances of children with special needs who include CWHA. Although the policy is there, CWHA suffer S\&D which infringe on the right to education of CWHA. The international AIDS conference aimed at eliminating S\&D through their watchword "no one left behind". This would support non-discrimination among CWHA However, Kerry [30] highlights that CWHA remain victims of HIV/AIDS related stigma thus excluding them from participation in learning activities. To eliminate HIV/AIDS related to S\&D among people with HIV/AIDS governments made commitment to reduce S\&D during the HIV/AIDS declaration in 2001 People with AIDS (PWA) who include young children aged 4-8 years.

Nevertheless, Kerry [30] reported that S\&D remained an impediment to response to HIV/AIDS epidemic. However despite devastating effects of $\mathrm{S} \& D$, no much attention and resources have been allocated as deserved. Studies by UNAIDS [31] established that PHA have been judged and found guilty of promiscuity behaviours. This has led to isolation, rejection; name calling and physical abuse. Children are protected by UNCRC (1995) and against discrimination.

The Kenyan constitution (2010) emphasizes on the right to free and compulsory education. However, GOK and UNICEF [29] indicated that HIV/AIDS had wide spread side effects on CWHA learning experiences which led to infringement of the right of child to participation in 8 learning. The study established that CWHA are subjected to various psychosocio impacts such as fright, stigma, anxiety, despair and uselessness. All these affect their learning experiences infringing on the right to education of CWHA. 
Gok and UNICEF [29] further found out that CWHA participation in learning was affected by many compounding issues which included being infected, failing to attend school, low performance and dropping out of schools. CWHA, whose parents are ailing or are dead, suffer from lack of love, guidance, basic requirements like food, clothing, uniforms, books and security. This affects their participation in learning activities in an inclusive school system. These manifest themselves in form of isolation, rejection, name-calling, physical abuse and child labour. S \& D in CWHA have often been associated with adverse effects including poor performance, low self-esteem and self- isolation [31, 32].

\section{Statement of the Problem}

The government of Kenya through enactment of various policies such as Child Act 2001, United Nations Convention on the Rights of the child 1991 and the Kenya Constitution 2010, has put measures to curb HIV/AIDS related S\&D as a means of allowing all children to access universal free primary education. Emphasis has been laid on nondiscrimination on the grounds of social status, socioeconomic or health and mental status of child. Studies done on HIV/AIDS related S\&D have focused on adults living with HIV/AIDS and especially those offering health care services. In Kenya little attention has been accorded to research in the area of stigma and discrimination. However, the few studies available have focused on adult people leaving with HIV/AIDS with minimal attention given to the experiences of CWHA. Thus this study aimed at investigating the effects of stigma and discrimination on the right to Education of children with HIV/AIDS aged 4-8 years in Kikuyu sub-county, Kenya.

\section{Purpose and Objectives}

The study was carried out to examine the impact of S\&D on the right to education CWHA in kikuyu sub county, Kiambu County. The study sought to find out the prevalence of isolation and rejection, experiences of physical and verbal abuse among CWHA and their effects on the self-esteem of CWHA. These findings would be useful to the organizations that deal with Child protection, preschool teachers and the Ministry of Education.

\section{Theoretical Framework}

This study was underpinned by Goffman's theory of social stigma. This theory stipulates that stigma is a trait, demeanor, or eminence which is socially demeaning in a certain way. It makes a person to be categorized by others in an unwanted, forbidden stereotype rather than in an acknowledged, normal individual. Goffman [5] defined stigma as a distinct kind of fissure between simulated social identity and genuine social identity. Society institutes the means of labeling persons and the complement of attributes felt to be normal and ordinary for members of each group.

Goffman [5] groups the person's relation to a stigma into three classifications. These lasses are stigmatized, normals and the wise. Smith [32] in his findings revealed the pervasiveness of the own, the wise, and normals as distinct groups; but, the wise were in two categories, the active wise and the passive wise. Active wise embraced thoughtprovoking stigmatization and enlightening stigmatizers, while passive wise felt otherwise. In line with this study stigma is exemplified in society.

\section{Conceptual Framework}

The variables of the study were used to substantiate the association between S\&D and participation of CWHA in learning. Isolation and rejection, physical and verbal abuse, lead to low self-esteem which in turn hinders participation of CWHA. S\&D is an inhibition to the actualization of the right to education of CWHA. Commitment to provision of free and compulsory education to all children regardless of their status has been barred by HIV/AIDS related S\&D.

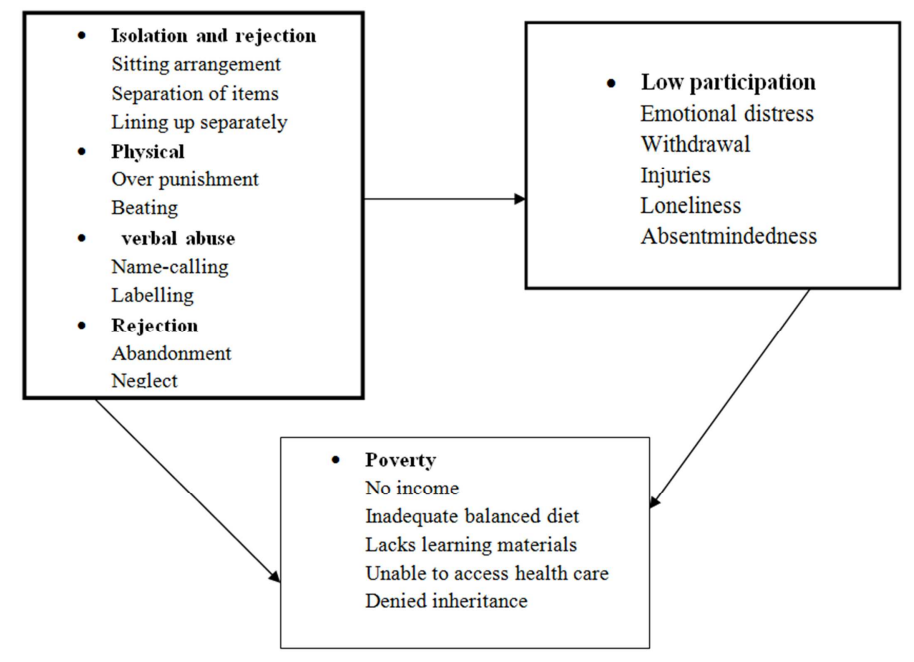

Figure 1. Conceptual framework. 
Figure 1 illustrates how HIV/AIDS related S\&D infringes on the right to education of CWHA through rejection, isolation, physical and verbal abuse. These manifestation lead to low participation due to withdrawal, shame, fear, loneliness, emotional distress, injuries and absentmindedness Regardless of the policies and the constitution protecting children from S \& D.

\section{Methodology}

The target population included 680 HIV/AIDS orphans and vulnerable children (OVC), 120 pre-school teachers, 240 caregivers and 34 administrators of civil society organizations (CSOS). A sample of 68 OVCs, 4 CSOs, 12 teachers, and 24 caregivers were randomly selected and a survey design was used. Data was collected through questionnaires, interview schedules, storytelling sessions and observation schedules. Descriptive statistics like percentages, frequencies and tables were used in the analysis of data. Content and interpretive analysis was also used to analyse quantitative data to establish the magnitude of the impact of $\mathrm{S} \& \mathrm{D}$ on the rights of CWHA.

\section{Results}

The study sought to establish the prevalence of isolation and rejection among CWHA aged 4-8 years in Kikuyu subcounty, Kenya. Table 1 below shows how isolation and rejection were manifested.

Table 1. Table 1 indicates that 100\% respondents (caregivers and administrators) believed that isolating CWHA in the sitting arrangement was practiced in the classroom.

\begin{tabular}{|c|c|c|c|c|c|c|c|c|}
\hline Manifestation & Administrators (F) & $\%$ & Care-givers (F) & $\%$ & Children (F) & $\%$ & Teachers $(\mathbf{F})$ & $\%$ \\
\hline Sitting arrangement & 4 & 100 & 24 & 100 & 0 & 0 & 00 & \\
\hline Separation of items & 4 & 100 & 22 & 91.7 & 60 & 88.2 & 00 & \\
\hline Neglect & 4 & 100 & 20 & 83.3 & 12 & 100 & 975 & \\
\hline abandonment & 3 & 75 & 22 & 91.7 & 12 & 100 & 975 & \\
\hline Withdrawal & 0 & 0 & 0 & 0 & 39 & 57.3 & 866.7 & \\
\hline
\end{tabular}

This was in agreement with studies done by Parker, and Aggleton [3]. They [3] confirmed that parents of 'normal' children are reluctant to allow their children interact; play, share anything with an infected child or affected. This had implication on the performance CWHA. Indeed the guardians/care-givers in the interview confirmed these allegations. Such practices forced CWHA to drop out of schools. CWHA confirmed the same during the story telling session. One child said:

Every day in the morning when I wake up to go to school, I cry. Not that I don't like learning, but when I think I will sit alone, I feel hated. In my class I sit alone but the teacher tells me I am her friend and does not want other children to disturb me. I don't like it but teacher insists on that. Can you come and tell her to let me sit with others?

According to table 1, 91.7\% Caregivers, $100 \%$ administrators and $88.2 \%$ CWHA confirmed that items used by CWHA were stored in separate containers both at home and school. In addition, CWHA cleaned their on items and stored in special containers different from others. As a result of these acts CWHA became withdrawn as shown by $57.7 \%$ respondents.

In the story telling with the children and interview with the caregivers the study established that CWHA were in fact discriminated and other children who refused to play with them. This contradicted what Mayer [33] that children needed love and security to develop well and be able to participate in the learning process. One child had this story to tell:

When the bell rings for break I become anxious because I have no friends to play with.

During break and at home if I join other children when playing some stop playing. They sit down and pretend to be tired. When moulding, children in my class don't like sharing clay. I don't like moulding classes.

Such practices had implications on the self-esteem and performance of CWHA. They are unable to participate well in class activities as well as outdoor or co-curricular activities. This leads to withdrawal of CWHA. Withdrawal makes CWHA unwilling to learn, developed fear, unwilling to be associated with the groups; they are always on their own and in deep thoughts. Observation carried out during indoor and outdoor activities it was evident that CWHA are indeed withdrawn, lonely, absent minded or disturbed. $88.2 \%$ of children who had suffered S\&D liked keeping to themselves. This definitely in turn affected their school attendance and participation.

The study was to further establish whether CWHA aged 48 years in Kikuyu sub-county, Kenya experienced physical and verbal abuse. This is shown in table 2 below.

Table 2. The findings in Table 2 show that name-calling by teachers affected CWHA's education

\begin{tabular}{lllllllll}
\hline Manifestation & Administrators (F) & $\mathbf{\%}$ & Care-givers (F) & $\mathbf{\%}$ & Children (F) & $\mathbf{\%}$ & Teachers (F) & \% \\
\hline Name calling & 4 & 100 & 24 & 100 & 68 & 100 & 0 & 0 \\
Beating & 4 & 100 & 24 & 100 & 68 & 100 & 0 & 0 \\
$\begin{array}{l}\text { Over } \\
\text { punishing }\end{array}$ & 4 & 100 & 24 & 100 & 68 & 100 & 0 & 0 \\
\hline
\end{tabular}


They verbally abused. Words like kahurura, (slimmer or spreader) munugu, (from baboons) mukware (dry skin), mugui (having no control over sex associated with dog's way of doing it) were commonly used to describe CWHA. The administrators $(100 \%)$ and care-givers $(100 \%)$ also agreed with the statements of CWHA. The results collaborated a study done by Nyblade et al. [34] which revealed that PLHA experienced S\&D in form of name-calling. Such kind of stigma is shameful to CWHA which affected their participation in learning. They became withdrawn and less attentive. Studies by UNAIDS [31] also indicated that CWHA suffered S \& D in school environment. To confirm such malpractices, on CWHA had this to say;

One day as I walked home I overheard two neighbours saying in low tones, Wakahurura is going home (referring to the child). I did not understand why they called me by that name. I asked aunt (caregiver), she told me not to listen to the neighbours. I like being called by my name.

UNAIDS [31] Children like being appreciated and loved. When teachers and peers reject CWHA, they bar integration during learning participation which in turn infringes the right to education. $94.1 \%$ of the respondents ascertained this. CWHA informed the study that teachers were not friendly to them and did not show concern for their predicaments.

The study findings established that there was a relationship between stigma and discrimination and self-esteem among CWHA aged 4-8 years in Kikuyu sub-county, Kenya. The study revealed that there is a positive relationship between stigma and discrimination and self-esteem among CWHA aged 4-8 years. During an interview schedule one caregiver said:

I was forced to transfer my child after realizing that the child was always punished for feeling sleepy in the morning. After taking ARVS the child vomited and looked weak. I did not want to tell the teacher the truth for fear of stigma. But I think the teacher was guessing the problem of my child. She did not like my child, she did not bother to call me we discuss the child, I was hurt.

Retribution lowers a child self-esteem which interrupts child's participation in learning. Internal stigma expressed as defeatism and withdrawal lowers a child's involvement. In a research study conducted by UNAIDS [31] it was revealed that CWHA were socially rejected, financially insecure, guilty, depressed among others. Children who suffer from such malpractices are likely not to participate adequately in the learning process. Consequently, the rights of the child are infringed.

\section{Conclusion and Recommendations}

The study found out that CWHA were subjected to isolation and discrimination. This had implication on their performance. The affected children drop out of school or moved from one school to another. CWHA were denied right to education through name-calling by teachers. They experienced verbal abuse and marginalisation. The study revealed that there is a positive relationship between stigma and discrimination and self-esteem. The study concluded that CWHA suffer social rejection, financial insecurity, shame /guilt, low self-esteem, depression and other psychological problems. The study recommended creating enabling environment to increase visibility of CWHA in the society for practice and policies being put in place to ensure that CWHA access education and strengthening policies that protect CWHA from child labour.

\section{References}

[1] United Nations (1991). Convention on the rights of the child. United Nations, New York.

[2] International HIV/AIDS Alliance (2011). Integrating stigma reduction into HIV programming: lesson from African regional stigma training program ISBN: 978-1-905055-87-6 Sweden.

[3] Parker, R. and P. Aggleton, (2003) HIV and AIDS-related stigma and discrimination: a conceptual framework and implications for action. Social Science \& Medicine. 57(1): p. 13-24.

[4] Link, B. G. \& Phelan, J. C. (2001). Conceptualizing stigma. Annual Review of Sociology, 27, 363-385. London EC4P 4EE New York.

[5] Goffman E. (1963). Stigma: Notes on the Management of Spoiled Identity. Prentice-Hall. ISBN 0-671-62244-7.

[6] Visser MJ, Kershaw T, Makin JD, Forsyth BWC. (2008). Development of Parallel Scales to Measure HIV-Related Stigma. AIDS Behav. 759-771.

[7] Dijker, A. J., \& Koomen, W. (2003). Extending Weiner's attribution-emotion model of stigmatization of ill persons. Basic and Applied Social Psychology, 25, 51-68.

[8] Weiner, B., Perry, R. B. \& Magnusson, J. (1988). An attributional analysis of reactions to stigmas. Journal of Personality and Social Psychology, 55, 738-748.

[9] Hebl, M. R., Tickle, J., \& Heatherton, T. F. (2000). Awkward moments in interactions between non stigmatized and stigmatized individuals. In T. F. Heatherton, R. E. Kleck, M. R. Hebl 21 \& J. G. Hull (Eds.). The social psychology of stigma (pp. 243-272). New York: Guilford Press.

[10] Bos, A. E. R., Kok, G., \&Dijker, A. J. (2001). Public reactions to people with HIV/AIDS in the Netherlands. AIDS Education and Prevention, 13, 219-228.

[11] Meyer, I. H. (2003). Prejudice, social stress, and mental health in lesbian, gay, and bisexual populations: Conceptual issues and research evidence. Psychological Bulletin, 129, 674-697.

[12] Stutterheim, S. E., Pryor, J. B., A. E., Hoogendijk, R., Muris, P., \& Schaalma, H. P. (2009). HIV-related stigma and psychological distress: The harmful effects of specific stigma manifestations in various social settings. AIDS, 23, 23532357.

[13] Mak, W. W. S., \& Cheung, R. Y. M. (2008). Affiliate stigma among caregivers of people with intellectual disability or mental illness. Journal of Applied Research in Intellectual Disabilities, 21, 532-545. 
[14] Rusch, N., Corrigan, P. W., Todd, A. R., \& Bodenhausen, G. V. (2011). Automatic stereotyping against people with schizophrenia, schizoaffective and affective disorders. Psychiatry Research, 186, 34-39.

[15] Herek, G. M. (2009). Sexual prejudice. In T. Nelson (Ed.), Handbook of Prejudice. Mahwah, NJ: L. Erlbaum Associates.

[16] Pachankis, J.E. (2007). The psychological implications of concealing a stigma: A cognitive-affective-behavioral model. Psychological Bulletin, 133, 328-345.

[17] Stutterheim, S. E., Bos, A. E. R., Pryor, J. B., Brands, R., Liebregts, M \& Schaalma, H. P. (2011). Psychological and social correlates of HIV status disclosure: The significance of stigma visibility. AIDS Education and prevention, 23, 382392.

[18] Herek, G. M., Saha, S., \& Burack, J. (2013). (in press).Stigma and psychological distress in people with HIV/AIDS. Basic and Applied Social Psychology.

[19] Pryor, J. B., Reeder, G. D., \& Monroe, A. E. (2012). The infection of bad company: Stigma by association. Journal of Personality and Social Psychology, 102, 224-241.

[20] Struening, E. L., Perlick, D. A., Link, B. G., Hellman, F., Herman, D., \& Sirey, j. A. (2001). Stigma as a Barrier to Recovery: The Extent to Which Caregivers Believe Most People Devalue Consumers and Their Families. Psychiatric Services, 52, 1633-1638.

[21] Mak, W. W. S., \& Kwok, Y. T. Y. (2010). Internalization of stigma for guardiansof children with autism spectrum disorder in Hong Kong. Social Science \& Medicine, 70, 2045-2051.

[22] Phelan, J. C., Bromet, E. J., \& Link, B. G. (1998). Psychiatric illness and family stigma. Schizophrenia Bulletin, 24, 115126.

[23] Stutterheim, S. E., Pryor, J.B., Bos, A. E., Hoogendijk, R., Muris, P., \& Schaalma, H. P. (2009). HIV-related stigma and psychological distress: The harmful effects of specific stigma manifestations in various social settings. AIDS, 23, 23532357.

[24] Snyder, M., Omoto, A. M., \& Crain, A. L. (1999). Punished for their good deeds: Stigmatization of AIDS volunteers. American Behavioral Scientist, 42, 1175-1192.
[25] Pryor, J. B., Reeder, G. D., Yeadon, C., \& Hesson-McInnis, M. (2004). A dual-process model of reactions to perceived stigma. Journal of Personality and Social Psychology, 87, 436-452.

[26] Corrigan, P., \& Lam, C. (2007). Challenging the structural discrimination of psychiatric disabilities: Lessons learned from the American disability community. Rehabilitation Education, 21, 53-58.

[27] Scambler, G. \& Paoli, F. (2008). Health work, female sex workers and HIV/AIDS: G;lobal and local dimensions of stigma and deviance as barriers to effective interventions. Social Science and Medicine, 66, 1848-1862.

[28] Bauman L, Camacho S, Silver E, Hudis J, Draimin B. Behavioral problems in school-aged children of mothers with HIV/AIDS. Clinical Child Psychology and Psychiatry. 2002; 7: 39-54.

[29] UNICEF (2000).The state of the world's children 200.UNICEF New York.

[30] Kerry. M. / Traci. E and Laura N (2009). HIV-related stigma and discrimination a summary of actions or recent literature international centre for research on women to UNAIDS.

[31] Avert (2014). Reflection on the international AIDS conference 2014, west Sussex England.

[32] UNAIDS. (2007). HIV and AIDS - related stigmatization discrimination and denial: Forms, contexts and determinants, research studies from Uganda and India (prepared for UN AIDS. Geneva, UNAIDS.

[33] Smith, R. (2012). "Segmenting an Audience into the Own, the Wise, and Normals: A Latent Class Analysis of StigmaRelated Categories". Communication Research Reports (29 ed.): 257-65. doi: 10.1080/08824096.2012.704599.

[34] Mayer R. E. (2003), Learning and Instruction Pearson Education Inc. Upper Saddle River 287_88.

[35] Nyblade, L., Pande, R., Mathur, S., MacQuarrie, K. Kidd, R., Banteyerga, H., (2003). Disentangling HIV and AIDS: Stigma in Ethiopia, Tanzania and Zambia. Washington, DC: International Centre for Research on Women. Retrieved September 25, 2006, from UNAIDS, Country Progress Reports, 2012. 